\title{
Conversaçiones de Música a finals del segle XVI: el cas de l'acadèmia de Joan de Borja i Castro
}

\author{
Conversaçiones de Música at the late sixteenth Century: the Academy \\ of Juan de Borja in Madrid
}

FERrAN EsCRIVÀ-LLORCA

escrivaf@uji.es

Universitat Jaume I - Castelló

\begin{abstract}
Resum: Aquest article s'insereix dins del conjunt d'investigacions sobre la Cort dels Habsburgs. L'estudi de les acadèmies musicals és poc conegut. A partir d'algunes investigacions sobre acadèmies literàries, l'article focalitzarà en l'acadèmia musical que Joan de Borja i Castro tenia a Madrid. En aquest sentit, si el mecenatge literari cortesà ja és un tema amb múltiples variants, l'aproximació al patrocini d'altres activitats artístiques, com el cas de la música, ho és encara més. En les següents pàgines s'aprofundirà en les diverses facetes erudites de Joan de Borja amb el fil conductor de les acadèmies, com a centre d'intel lectualitat, de creació i promoció cultural i també personal. Per aquesta acadèmia van passar alguns dels personatges del món musical ibèric més important de l'època com Francisco Guerrero o Tomás Luis de Victoria. Aquest article pretén mostrar la importància d'aquesta acadèmia com un punt neuràlgic del mecenatge musical de les darreres dècades del segle XVI.
\end{abstract}

Paraules clau: Joan de Borja, Borja, acadèmies, Habsburgs, Música, Madrid

\begin{abstract}
This work is part of the research on The Court of Habsburg in Modern Era. The study of music academies is not quite known. From few works on literary academies, this article will focus on the music academy that of Juan de Borja i Castro hold in Madrid. In this way, if the courtly literary patronage is already an issue with multiple variants, the approach to other artistic activities, such as the music, it is even more. In the following pages, it will delve into the various aspects of erudition of Juan de Borja with the thread of the academies, as a centre of intellectual, creative and cultural promotion and personal. Some of the most important composers of the Iberian World of that time, such as Francisco Guerrero or Tomás Luis de Victoria, were involved in this academy. The article aims to show the relevance of this cenacle as a focal point of the musical patronage in the last decades of the 16th century Spain.
\end{abstract}

Keywords: Joan de Borja, Borja, academies, Habsburgs, Music, Madrid 
Ferran Escrivà-Llorca. Conversaçiones de Música a finals del segle XVI: el cas de l'acadèmia de Joan de Borja i Castro

\title{
1. Introducció
}

Aquest article s'insereix dins del conjunt d'investigacions sobre la Cort dels Habsburgs ${ }^{1}$ i contempla la complexitat en l'aproximació a l'estudi de les acadèmies entre els segles XVI i XVII on s'inscriuen alguns personatges borgians, i més concretament Joan de Borja i Castro. En aquest sentit, si el mecenatge literari cortesà és un tema amb múltiples variants, l'aproximació al patrocini d'altres activitats artístiques, com el cas de la música, ho és encara més.

En les següents pàgines s'aprofundirà en les diverses facetes erudites de Joan de Borja amb el fil conductor de les acadèmies com a centre d'intel·lectualitat, de creació i promoció cultural i també personal. Centrant-se en la música com element principal del què prové la investigació original, l'article també fa esment de les activitats de caire literari així com els subjectes d'erudició com la matemàtica o l'emblemàtica. Els textos poètics d'autoria o atribuïts a Joan de Borja no s'han inclòs per ser molts i no ser la temàtica principal de l'article, encara que s'hi fa referència alguns.

Aprofite les paraules de Santiago Martínez (2010: 36) per resumir com seria el model ideal de cortesà d'aquesta època:

\begin{abstract}
El noble de corte lee, regala, presta, intercambia y adquiere libros; también los hace trasladar manuscritos, discurre sobre su contenido, sufraga a sus autores y respalda las ediciones, negocia con libreros y ajusta sus precios según sus prioridades; acude a academias literarias, a menudo patrocinadas y presididas por él, en donde escucha, platica, jalea, interrumpe e incluso recita sus propias rimas cuando no escamotea las ajenas. Asiste a comedias y autos. Participa en tertulias y cenáculos menos concurridos al amparo de antecámaras, huertas y casas particulares, y allí observa ocioso, interviene y representa en compañía de damas y galanes obras breves, compite en justas poéticas por simbólicos galardones, "ofreze discursos" e incluso canta. Lo que hoy denominamos Siglo de Oro en otro tiempo ya era visto como un tiempo de ingenios nobiliarios.
\end{abstract}

Més endavant tornarem a les acadèmies del Siglo de Oro però convé mostrar de forma breu els antecedents de les acadèmies. Aquests es poden resseguir fins l'època antiga però és a la Itàlia renaixentista on hom considera que s'estableix el model d'acadèmia literària i erudita que lluiria i es perfeccionaria durant els segles XVI i XVII. Els estudis sobre acadèmies literàries són abundants i com que no són el motiu central d'aquest article, no m’hi detindré massa. Tal vegada, un dels models de cenacle erudit a l'Edat Moderna que perdurarien en l'imaginari col lectiu dels nobles seria el descrit als diàlegs de Il libro del Cortegiano on s'hi troben ja els elements que configurarien les acadèmies a finals del XVI. ${ }^{2}$ Segons Peter Burke (1998: 64) el fet que l'escriptor venecià Sansovino deixés per escrit en 1582 la seua interpretació del llibre de Castiglione com "la famosa acadèmia"

1 Sobre discussions historiogràfiques i nomenclatura acadèmica actuals sobre els Àustries i Habsburgs recomane Martínez Millán (2013).

2 Empraré d'ara endavant el títol El Cortesano perquè probablement és el que coneixerien els autors citats a l'article a través d'alguna de les edicions impreses a la Península Ibèrica sense descartar-ne d'altres (Burke 1998: 180-186).

SCRIPTA, Revista internacional de literatura i cultura medieval i moderna, núm. 9 / juny 2017 / pp. $312-323$

ISSN: 2340 - 4841 doi:10.7203/SCRIPTA.9.10349 
Ferran Escrivà-Llorca. Conversaçiones de Música a finals del segle XVI: el cas de l'acadèmia de Joan de Borja i Castro

—interpretant així que els diàlegs a El Cortesano són un ideal de noblesa i de la manera de procedir en les discussions sobre temes de diversa índole-, fa plausible que la major part de membres de les acadèmies (italianes i d'arreu d'Europa) empraren aquest llibre com a manual d'ús. Un altre autor, José Sánchez (1961: 235-243), interpreta el text de Castiglione de la mateixa manera i vincula imitadors posteriors. Algunes de les paraules que l'autor italià ressaltava de Guidubaldo són parafrasejades, ja a principis del segle XVII, per Lupercio Leonardo de Argentola, suposadament, a l’acadèmia saragossana de los Anbelantes (Sánchez 1961).

Trobem doncs que una acadèmia era un lloc de trobada de nobles i homes de $p$ lum $a{ }^{3}$ versats $i$ erudits on hi predominava l'intercanvi de coneixement però amb unes finalitats concretes. Roberto Weiss (1960: 69-93) opinava que les acadèmies, i no les universitats, van ser les transmissores dels coneixements humanistes a l'Edat Moderna. Per una banda el lleure i el conreu del cavaller cortesà — amb l'ideal de Castiglione_ i per altra banda, com un dels llocs preponderants per a mantenir relacions de clientelisme i mecenatge. Encara que la concepció del mecenatge no ha tingut històricament la mateixa consideració segons fóra artístic, literari, musical, etc. podem convenir que les relacions clientelars $i$ de mecenatge inserides a l'àmbit cortesà tenen diversos graus de dependència en diverses moments i situacions (Marín 2015: 36).

Cite Castiglione i Leonardo de Argensola per introduir la figura de Joan de Borja i Castro (15311606). Aquest noble, segon fill baró de Sant Francesc de Borja, va ser educat en perfecta sintonia amb els preceptes que marcava l'autor de El Cortesano, com ho havia estat també el seu pare (La Parra 2012: 94-103). La seua formació també va estar molt influenciada pel contacte directe i continu amb la Companyia de Jesús. Joan de Borja va tindre una trajectòria política prototípica de fill noble fadristern de casa gran —els Borja eren Grandes de España-. Una primera època de tasques governatives, al servei de la princesa Juana de Àustria i del majordom reial Ruy Gómez de Sílva, príncep d'Èboli, que li va servir per forjar-se una carrera i un respecte a la cort de Felip II mentre compaginava tasques executives per a la facció ebolista (Martínez Millán 1994). Des de 1569 fins 1575 va ser ambaixador a Portugal i posteriorment, a partir de 1576, el cap de la diplomàcia a la cort de l'Emperador Rodolf II. A Praga, va encapçalar la facció espanyola juntament amb l'emperadriu Maria d'Àustria (Marek 2013: 75-81). Aquesta el va nomenar majordom major de la seua casa en 1581, any en què va retornar a Madrid. Joan de Borja va ocupar aquest càrrec fins la mort de l'Emperadriu en 1603 i altres posicions destacades, especialment des de l'arribada al poder del valido de Felip III, el duc de Lerma, que era nebot seu.

Les vinculacions de Lupercio Leonardo de Argensola —i també amb el seu germà Bartolomésón més conegudes i més estretes. El primer va ser durant alguns anys secretari de l'emperadriu Maria, mentre que el seu germà era capellà, durant els anys que Borja era majordom major. Les dates exactes de la presència dels germans Leonardo de Argensola al servei de l'Emperadriu no són

\footnotetext{
3 No tinc notícies concretes sobre la participació de dones a acadèmies borgianes. Sobre la participació de dones en acadèmies recomane Mazuela-Anguita (2012: 303-310).
} 
del tot clares. Hom sap que ambdós havien estat al servei dels ducs de Villahermosa - a meitat de la dècada dels 80-, Fernando de Aragón de Gurrea i Juana de Pernestán, el matrimoni dels quals havia arranjat Borja a Praga (Marek 2011: 59). Queda clar que la relació d'ambdós germans amb Borja era estreta dins i fora de las Descalzas Reales.

\section{Acadèmies Borgianes}

Lope de Vega feia esment de l'afició pel conreu erudit dels nobles cortesans: "ningún siglo han conocido España tantos príncipes que con tal gracia, primor, erudición y puro estilo escriban versos, como son tan evidente ejemplo el conde de Lemos, el de Salinas, el marqués de Cerralvo, el comendador mayor de Montesa, el duque de Osuna, el marqués de Montesclaros y el doctísimo duque de Gandía" (Martínez Hernández 2010: 36). Tant Francisco de Borja y Aragón, príncep d'Esquilatxe com Fernando de Borja y Aragón, comendador major de Montesa —ambdós fills de Joan de Borja- s'hi troben entre el reduït cercle de nobles cortesans que van liderar el Siglo de Oro. Ambdós, especialment el primer, són reconegut com a poetes menors propers als cercles de Lope de Vega (Escrivà-Llorca 2015: 16). ${ }^{4}$ Cal remuntar-nos dècades enrere per trobar un antecedent remarcable. Sens dubte, l'acadèmia musical de Joan de Borja a Madrid era la més reeixida de l'època.

Un altre observador de començament del segle XVII indicava que "De todas estas occasiones y comodidades para más fácilmente deprender y más despresto, la España es harto falta; lo qual vemos por exemplo en esta Corte, pues entre tantos caualleros, condes, marqueses, duques y príncipes que moran en ella, no ay ninguno (que yo sepa) se deleyte de música ni quien dé comodidad para hazer estas acadèmies (...)Y si tengo que dezir verdad, digo que no hallo más que uno que guste tener en su casa semejante exercicio: y este señor es Don Juan de Borja, Mayordomo mayor de la S.C.M. emperatriz María de Austria” (Cerone 1613: 151). Si bé caldria posar en context les paraules escrites per Pietro Cerone, tenint en compte l'ascendència italiana i el cert rebuig que s'hi detecta de la seua estada a la capella reial de Felip III, mostren l'existència d'aquesta acadèmia a partir d'una visió perifèria i, tal vegada, esbiaixada. Açò és degut a que ben probablement Cerone no era un convidat tan habitual com voldria a participar en les "conversacions de música”, lloc de recreació i erudició musical però també de patrocini de les lletres i arts.

Si bé ambdós escrits parlen, més o menys, de la mateixa època, en principi no seria del mateix tipus d'activitats. Sens dubte, a les acadèmies literàries de finals del segle XVI i principis del XVII la música hi estava present i, a falta d'estudis més acurats, és possible afirmar que la música també era un tema principal. Cerone no s'equivocava en la comparativa amb les acadèmies italianes. A Itàlia, com també a França, les acadèmies exclusivament musicals es distribuïen per tota la seua geografia des

4 Resulta molt interessant i suggeridora de noves recerques l'anècdota de la visita del cardenal Barberini al palau del príncep d'Esquilatxe en 1626, on s'explica que Francisco de Borja no hi estava però van trobar tot de músics preparantse per a una velada (Simón Díaz 1980). 
Ferran Escrivà-Llorca. Conversaçiones de Música a finals del segle XVI: el cas de l'acadèmia de Joan de Borja i Castro

de mitjan del segle XVI. A Verona, Florència, Siena, Roma, Venècia, Mantua, s’interpretava música patrocinada per nobles i es discutia sobre teoria musical. I el que tal vegada fóra més important, moltes d'aquestes acadèmies publicaven les seues discussions i conclusions. En el cas d'Espanya, hi ha un component a tindre en consideració. Segons Cristina Diego (2009: 38) "mientras los poetas franceses e italianos del siglo XVI no tienen reparos en imprimir sus obras puestas en música, los poetas españoles confían sus obras a impresos de manera muy puntual, prefieriendo la transmisión oral o manuscrita". Aquesta podria ser, en part, una de les causes de per què s'hi conserven pocs exemplars de poesia musicada del segle XVI i XVII, ja que degudes les dificultats en els processos d'impressió aquesta tasca editora era molt més complexa. També podria explicar-se, en part, degut a què no es conserven abundants notícies de les activitats de les acadèmies si bé cal tenir en consideració altres propostes sobre la oralitat a les acadèmies que proposa Esther Lacadena a partir d'idees de Margarit Frenk (Lacadena 1988).

Alguns del textos conservats amb autoria o atribuïts a Joan de Borja són també prova fefaent que Borja participava en acadèmies. Els textos conservats a la Biblioteca Nacional de España i la Real Biblioteca contenen referències explícites als destinataris com el cas de "Soneto a los Académicos". No em detindré sobre aquestes obres per no ser el tema principal d'aquest article i, a més, haver estat ja objecte d'alguns treballs per part de Labrador, DiFranco i Cach (1988) i Baranda (2009). Aquests estudis versen sobre el Cancionero de Pedro de Rojas (Mss/3924 de la Biblioteca Nacional de España) que conté obres d'autors que hagueren pogut participar en algun tipus d'acadèmia on cal destacar que participarien dones. Altres poemes de Borja es conserven a la Real Biblioteca amb la signatura II/570 i II/1578.

Així mateix, són conegudes les participacions de Joan de Borja a l'acadèmia de Fernando Álvarez de Toledo y Pimental, III duc d'Alba qui era un gran patrocinador de "justas y conferencias". Bartolomé Leonardo de Argensola descrivia aquesta acadèmia — tant a Madrid com a "La Abadía" (Càceres) com un encontre de nobles erudits a l'estil d'Itàlia (Bouzá 1994: 460-461) entre qui es trobaven, a més de Joan de Borja, personatges clau en l'educació del príncep don Carlos com Cristóbal Moura, Juan de Idíaquez o Juan de Silva. ${ }^{5}$ Totes les notícies, documentació i interpretacions conflueixen a mostrar Joan de Borja com una personatge extremadament culte i erudit. També ho era en disciplines com les matemàtiques, la cosmografia i la cartografia. Certament, la seua condició de diplomàtic ho feia necessari. En aquest sentit, les relacions amb Francisco de Holanda, Juan Bautista Gesio i Luis Jorge Barbuda —al servei de Borja com a cartògraf i espia—, ${ }^{6}$ són també una mostra de l'interès que tenia per aquestes disciplines, així com la participació en l'acadèmia de matemàtica de Juan Herrera (Esteban 1999: 128).

5 Sobre la pertinença a faccions polítiques i grups de poder i la historiografia de cort, recomane la reflexió al respecte de Bouzá (1994: 461).

6 Luis Jorge Barbuda és possiblement l'autor dels gravats de Empresas Morales (1581) com indicava Borja en una carta a Manuel Coresma Barreto en 1575 "así mismo me tiene començado a hazer un libro de empresas" (Deswarte-Rosa 1987: 169).

SCRIPTA, Revista internacional de literatura i cultura medieval i moderna, núm. 9 / juny 2017 / pp. 312-323 ISSN: 2340 - 4841 doi:10.7203/SCRIPTA.9.10349 
Si bé la informació conservada és escassa, tot fa indicar que Joan de Borja va tindre contactes amb algun ambient similar a una acadèmia durant la seua estada com ambaixador a Lisboa. Coneguda l'afició per les lletres i la música, és ben probable l'establiment de vincles amb alguns cenacles literaris entre els que Francisca de Aragón, que esdevindria la seua segona muller al poc d'acabar la missió diplomàtica lusitana, despertava fervorosa admiració. Aquesta alta dama, al servei de la reina àvia Catarina d'Àustria, era destinatària de nombrosos poemes de la ploma de Luis Camões, Jorge de Montemayor, Pedro Andrade i Dom Manuel de Portugal — ambaixador portugués a Castella—. Almenys una peça d'aquest darrer dedicada a Francisca de Aragón, i amb música d'autoria anònima, es conserva copiada al Cancionero de Elvas (P-Em 11793) ${ }^{7}$ i al Cancionero de Belem (P-Lma 3391), essent ambdues peces concordants (Escrivà-Llorca 2015: 128).

Més suggeridora resulta la idea dels encontres erudits de Joan de Borja a Praga i Viena. Amb la hipòtesi de treball que l'entorn de l'emperadriu Maria tenia encontres literaris i musicals a Praga, vaig començar a indagar sobre aquest tipus d'activitats durant els anys que va durar la missió diplomàtica de Borja. Si entenem com necessàries algunes premisses per a poder parlar d'una acadèmia, podríem convenir que aquestes haurien de ser, sense ser-hi excloents ni haver de complirse totes: a) la participació d'un nombre reduit de nobles curiosos, homes de lletres i música, tots amb un esperit d'erudició i intel lectualitat, àvids de coneixement; b) un lligam amb una institució educacional, per exemple una universitat o un col legi; c) una sèrie de publicacions vinculades a aquesta acadèmia, patrocinades per la pròpia acadèmia, o bé, per part d'algun dels seus membres; d) unes idees comunes i principis compartits pels participants.

Robet Evans en el seu ja clàssic estudi sobre la cort de Rodolf II, explica com a meitat de la dècada de 1570 es va instaurar el moviment acadèmic protestant a la ciutat bohèmia liderat per Daniel Adam de Veleslavín. La universitat, influenciada pel moviment reformista hussita, es va convertir en un dels pols protestants de la ciutat i, al mateix temps, en un dels primers llocs d'encontre amb esperit acadèmic a la manera italiana. Marek Bydžovský, rector de la universitat i professor d'història i matemàtiques, feia esment als seus escrits que ensenyava com Akademie (acadèmia) o Pražské uČení — literalment, "on s'ensenya a Praga”- A Praga hi havia desenvolupades, també, les activitats pròpies de l'edició de llibres. Veleslavín havia estat un dels iniciadors però van ser Jan Kocín o Joan Opsimathes qui van establir-ne la vinculació amb la universitat protestant. Si bé, no es podia comparar la publicació de llibres lligats a l'acadèmia, tal com es feia a Itàlia, sí que resulta significatiu entendre que aquestes edicions venien a estimular i completar els encontres d'aquest cercle d'erudits (Evans 1984: 134).

En oposició a aquesta acadèmia s'hi trobaven les activitats erudites de la facció catòlica o prohispànica. Tot girava al voltant de Maria d'Àustria i de l'ambaixada espanyola com a garant de la fe i la influència política del Rei. Al capdavant de l'ambaixada s'hi trobava l'ambaixador de torn, actuant

7 Signatura RISM (http://www.rism.info/en/sigla.html). 
Ferran Escrivà-Llorca. Conversaçiones de Música a finals del segle XVI: el cas de l'acadèmia de Joan de Borja i Castro

de $b r o k e r^{8}$ del monarca, amb un seguit de secretaris sense gran llinatge encara que la major part d'ells amb un alt nivell intel lectual $\mathrm{i}$ bon coneixedors de l'entramat cerimonial i de les xarxes clientelars imperials (Marek 2013: 39-52). Cal sumar-hi a tot açò l'estreta vinculació amb la Companyia de Jesús, que posseïa el col legi Clementinum al bell mig de l'antiga ciutat—on Borja va ser professor de poètica (ex schola poetica) —, principals benefactors de la política clientelar d'aquesta facció. I finalment, les famílies nobles catòliques més importants de l'entorn de l'emperador com els Dietrichstein, Pernestejn, Ro $\square$ mberk i Lobkowicz (Evans 1984: 34). Aquest entramat divers resultava d'allò més propici per desenvolupar aquesta mena d'activitats acadèmiques.

A falta de documentació directa que corrobore la presència d'una acadèmia formal a l'entorn de l'Emperadriu, sí és factible pensar en l'existència de quelcom semblant. Centrant-me en el anys que Borja va estar al capdavant de la legació, s'hi complirien cadascuna de les premisses anteriorment citades: hi participaven els nobles — les famílies bohèmies i espanyoles_-, el personal administratiu de l'ambaixada — coneguts són els noms de Pedro Cornejo o Álvaro de Veancos- i membres de la casa de l'emperadriu Maria — com per exemple Mateu Fletxa el jove, capellà_. D'altra banda, els vincles amb els jesuites eren molt potents i, concretament en el cas del Clementinum, Borja figura com un dels fundadors d'una confraria mariana. ${ }^{9}$ Pel que fa a les publicacions que podrien estar vinculades a una hipotètica acadèmia, l'any 1581, abans de marxar de tornada a Madrid, Borja va fer publicar a l'impremta de Jiř́ Černý (Georg Nigrin), amb pocs mesos de diferencia, el seu llibre d'emblemes juntament amb dues edicions de música de Mateu Fletxa i una reedició del llibre de Pedro Cornejo. ${ }^{10}$

Si a aquestes evidències s'hi suma les idees comunes de religiositat catòlica, ${ }^{11}$ la influència del poder reial i la important presència de membres l'orde militar de Sant Jaume a Praga, configuren un ambient propici per a l'existència d'algun cenacle semblant a una acadèmia.

8 Denominació comuna en la investigació històrica moderna (Martínez Millán 1992: 22-23).

9 Joan de Borja ja formava part de la confraria de Corpus Christi que representava les quatre grans nacions catòliques amb important presència a Praga que havia fundat Jacob Chimarrhaeus, almoiner i cantor de la capella de Rodolf II. La constitució d'aquesta confraria recorda molt a les al legories de Giussepo Arcinboldo on aquest dividia Europa en quatre parts i com a cap suprem hi ha via l'Emperador (Lindell 1994: 261).

10 Historia de las civiles guerras y rebelión de Flandes, recopilada, enmendada y añadida en este última edición hasta la fin del anno de ochenta, (30 d'abril); Las Ensaladas (30 de juny); Empresas Morales (1 de juliol). Darrera la publicació de Divinarum Completarum pslami (8 d'agost) de Mateu Fletxa no hi ha cap constància que hi estiga la mà de Borja però aquestes obres anaven destinades per a l'ús, presumiblement, de la confraria de Corpus Christi (Escrivà-Llorca 2015: 95-96).

11 Joan de Borja, d'igual manera que l'Emperadriu, eren àvids col leccionadors de relíquies. (Escrivà Llorca 2017) Sobre la prevalença i la interpretació de la Pietas Austriaca vegeu Coreth (2001) i Teresko (2014). 
Ferran Escrivà-Llorca. Conversaçiones de Música a finals del segle XVI: el cas de l'acadèmia de Joan de Borja i Castro

\section{Una Acadèmia de Música a Madrid}

Molt poques són les notícies i documentació sobre l'acadèmia de Joan de Borja. He preferit subtitular "de Música" per ser aquestes menys habituals i ser el principal motiu d'un apartat de la meua tesi doctoral (Escrivà-Llorca 2015: 123-137). A través de l'estudi d'aquest tipus d'acadèmies és poden interpretar millor algunes relacions, discretes, entre membres nobles i músics de l'època, que donen una perspectiva més ampla del món musical de la cort dels Àustries (Sanhuesa 1998 i Mazuela-Anguita 2012: 333-342).

La notícia més coneguda en a l'àmbit musicològic és l'esmentada referència que fa Pedro Cerone (1613: 151). Aquest havia arribat a Madrid des de Sardenya en 1593 i va entrar al servei de Jacopo Gratiis (més conegut com el Caballero de Gracia), possiblement l'únic altre noble que tenia una acadèmia de música a la capital. Cerone va poder, finalment, entrar a la capella reial ben probablement amb l'ajuda d'alguns dels nobles que passaven per les acadèmies musicals de Madrid. Un altre document que demostra l'existència d'aquesta acadèmia musical de Joan de Borja és una carta que Francisco Guerrero, mestre de capella de la catedral de Sevilla, li va enviar a Borja en 1598. ${ }^{12}$ Aquesta missiva dona resposta a moltes de les qüestions plantejades i permet entreveure el grau de patrocini que Borja exercia sobre les activitats musicals a Madrid.

En aquesta carta, Guerrero demana una mercè a l'emperadriu Maria per poder retirar-se del mestratge de capella de la catedral sevillana. I ho fa a través del seu majordom major, tot recordantli les vinculacions que havia tingut amb aquest: Guerrero havia estat paje de la casa del seu pare durant l'estada a Barcelona com a virrei de Catalunya, a més dels recordats encontres musicals promoguts per Borja com rememora "y después V[uestra] S[eñoría] en esa corte me a hecho muchos favores, admitiéndome en su conversaçión de música". Resulta evident que aquesta "conversación de música" fa referència explícita a una acadèmia musical. El mestre sevillà seria bon coneixedor de les destreses musicals de Joan de Borja, especialment amb les violes d'arc. Per això, juntament amb la carta, enviava un motet —avui perdut— en honor a les honres fúnebres de Felip II: "Aí enbío a V[uestra] S[eñoría] un motete q[ue] e echo para las honras del rey, n[uest]ro s[eñor], q[ue] sea en gloria. Suplico a V[uestra] S[eñoría] lo vea y cante con sus vigüelas de arco”. Més enllà de la relació entre mecenes i patrocinat, aquesta informació corrobora una de les pràctiques musicals conegudes però poc estudiades a l'entorn cortesà — la interpretació de motets amb instruments de corda - tot vinculant-ho amb la possessió d'aquests instruments per part de Joan de Borja. A l'inventari post-mortem de Borja, realitzat en 1606, s'hi troben dos jocs de violes d'arc: "Una caja de madera pintada de verde con cinco bigüelas de arco" i "Seis bigüelas de arco en una caxa" (Dadson 2006). Les violes d'arc eren instruments propis de les cases nobles - el III duc de Gandia posseïa música per aquestes en la seua biblioteca de Gandia (Pastor Zapata 1992: 304)— sovint emprades

12 Carta de Francisco Guerrero a Joan de Borja. Sevilla, 9 de novembre de 1598. British Library Add. 28426, doc. 36, f. 72 . 
a la música de cambra, és a dir, també a les acadèmies. A més, sovint s'hi troben notícies de l'ús d'aquests instruments en celebracions religioses i a l'aire lliure, així com la presència de violers i intèrprets a les nòmines reials des de 1546 (Escrivà-Llorca 2015: 133). Si important era la col lecció d'instruments que Borja posseïa al seu palau a Madrid, destaquen encara més, per singularitat, vàlua i quantitat, els llibres de música. Aquests també van ser taxats i la major part d'ells adquirits pel duc de Lerma en 1607 (Dadson 2006). Un estudi profund ha permès reconstruir aquesta "biblioteca" així com saber-ne la localització actual de les fonts i la importància que aquesta va tindre en el seu moment, amb tota probabilitat vinculats a l'acadèmia, i la transferència continuada d'objectes culturals entre diverses corts dels Habsburgs (Escrivà-Llorca 2015: 187-225) ${ }^{13}$.

Entre els noms lligats al món musical que haurien participat a l’acadèmia de música de Joan de Borja, a banda de Francisco Guerrero, caldria considerar Tomás Luis de Victoria, capellà de l'emperadriu a las Descalzas Reales i taxador dels llibres en l'inventari post-mortem de Borja. Mateu Fletxa el jove hauria estat present tant a Praga com a Madrid essent com era un compositor d'ensalades, gènere musical que podríem considerar d'una forma anàloga als emblemes. Com s'ha mostrat anteriorment, Pietro Cerone va ser un dels que coneixia de primera mà l'ambient de les acadèmies a la cort i així com també Géry de Gershem, tinent de la capella reial. La nòmina de nobles seria extensa així com la d’il lustres lletrats com mostren alguns estudis (Martínez Hernández 2010: 50, 67). Aquesta acadèmia va servir d'alguna manera de nexe d'unió i lloc catalitzador per vehicular el patrocini musical d'un cercle virtuós on conflueixen l'emperadriu Maria i el cardenal Rodrigo de Castro, amb Tomás Luis de Victoria i Francisco Guerrero com a protegits i on les figures de Joan de Borja i, també, l'ambaixador imperial Hans Kevenhüller van tindre un paper molt destacar (Vicente 2008: 20).

\section{Conclusions}

Com s'ha mostrat a l'article, l'estudi de les acadèmies musicals a la cort dels Habsburg és encara un tema amb pocs estudis i amb potencial per a futures recerques. L'acadèmia de Joan de Borja és, només, una mostra d'aquest tipus de cenacles del què hi ha notícies però el seu estudi és complex per les característiques de la documentació conservada i fragmentària. Al mateix temps però, l'aproximació a l'estudi d'aquest tipus de reunions propicia la recerca en les xarxes de mecenatge i una visió metodològica des de la història cultura molt enriquidora.

El món de les acadèmies literàries, on van ser protagonistes altres membres de la família Borja, requereix encara un nou enfocament des d'altres punts de vista per tal de donar cabuda a les activitats musicals i d'altres vinculades al camp erudit. L'estudi de la faceta literària de Joan de Borja

13 Els llibres de música de Joan de Borja es vinculen amb el treball de recerca sobre l'ambaixador Wolfgang Rumpf de Wielross i els seus llibres de música (en part, la coneguda com Colección Uclés). (Escrivà-Llorca 2013). L'article "On the Trail of a Knight of Santiago: Collecting Music and Mapping Knowledge in Renaissance Europe” escrit per Erika S. Honisch, Tess Knighton i Ferran Escrivà-Llorca està pendent de publicació. 
Ferran Escrivà-Llorca. Conversaçiones de Música a finals del segle XVI: el cas de l'acadèmia de Joan de Borja i Castro

requeriria una aproximació per part d'especialistes ja que, sense ser d'un nivell comparable amb la del seu fill, el del príncep d'Esquilatxe, ni al poetes menors del seu temps mostra que el conjunt d'activitats culturals de les elits nobles (i diplomàtiques) era extens i, a més, serveix per posar en valor els mecenatges que envolten aquesta època.

En l'estudi d'aquesta l'acadèmia conflueixen els tres elements principals per entendre la relació de Borja amb la música: la seua formació, protagonitzada per una forta influència de son pare i dels jesuïtes; la carrera diplomàtica que li va permetre aconseguir un perfil polític i cultural poc habitual entre els nobles de la seua condició; i la lleialtat a la casa d’Àustria, entesa com una adhesió incondicional —estratègica sempre—, i pròpia de tota la família Borja, sempre buscant estar a prop del poder, ja fóra Roma o Madrid. Aquesta combinació d'elements no és arbitrària sinó ben buscada i és possible trobar-la també en altres nobles. Borja pot considerar-se un noble prototípic que va manifestar el seu estatus social no només amb grans col leccions de pintura, relíquies o llibres sinó compartint l'afició musical tant amb altres nobles erudits com amb músics professionals. Els exemples d'erudició i gaudi musical converteixen Joan de Borja en un primus inter pares pel que fa a la música entre els nobles del seu temps. Un mecenes musical que va tindre en la seua acadèmia un punt neuràlgic de la vida cultural entre la dècada de 1580 i el 1601 quan Felip III va decidir traslladar la seua cort a Valladolid. 
Ferran Escrivà-Llorca. Conversaçiones de Música a finals del segle XVI: el cas de l'acadèmia de Joan de Borja i Castro

\section{Bibliografia}

Baranda, N. (2009) "Notas para un cancionerillo de poetas cortesanas del siglo XVI", Mujeres en la literatura. Escritoras, 19, pp. 8-27.

Bouzá Álvarez, F. (1994) "Corte es decepción. Don Juan de Silva, conde de Portalegre”, dins Martínez Millán, J. (ed.), La corte de Felipe II, Madrid, Alianza Editorial 1994, pp. 451-502,

Burke, P. (1998) Los avatares de El Cortesano. Lecturas y lectores de un texto clave del espiritu renacentista, Barcelona, Gedisa.

Cerone de Bergamo, P. (1613) El Melopeo y Maestro, Nápoles, Iuan Bautista Gargano i Lucrecio Nucci.

Coreth, A. (2001). Pietas Austriaca, Lafayette, Purdue University Press.

Dadson, T. (2006) "Music Books and Instruments in Spanish Golden-Age Inventories: The Case of Don Juan de Borja (1606), dins Fenlon, I. i Knighton, T. (eds.), Early Music Printing and Publishing in the Iberian World, Kassel, Reichenberger, pp. 95-116.

Deswarte-Rosa, S. (1987) “De l'emblema á l'espionnage: autour de Don Juan de Borja, ambassadeur espagnol en Portugal», dins As Relações artísticas entre Portugal e Espanha na época dos descobrimentos, Coimbra, Livraria Minerva, pp. 147-183.

Diego Pacheco, C. (2009) "Circulación y producción del madrigal en España durante el siglo XVI: el caso de Francisco de Montanos”, Revista de Musicología XXXII, 2 , pp. 35-49.

Escrivà-Llorca, F. (2013) "Los libros de música de un caballero de la Orden de Santiago: nuevos datos acerca de la Colección Uclés", Música, Revista del Real Conservatorio Superior de Música de Madrid, 20, pp. 131-137.

Escrivà-Llorca, F. (2015) Eruditio, Pietas et Honor: Joan de Borja i la música del seu temps (1533-1606), tesi doctoral, Gandia-València, Universitat Politècnica de València.

Escrivà-Llorca, F. (2017) “The Procession of the Relics of São Roque (Lisbon, 1588): A Royal Entry?", dins Knighton, T. i Mazuela-Anguita, A. (eds.) Hearing the City in Early Modern Europe, Turnhout, Brepols (pendent de publicació).

Esteban Piñeiro, M. (1999) “Los cosmógrafos del Rey”, dins Lafuente, A i Moscoso, J. (eds.) Madrid, Ciencia y Corte, Madrid, CSIC, pp. 121-133.

Evans, R. (1984) Rudolf II and His World: A Study in Intellectual History, 1576-1612, Oxford, Oxford University Press.

La Parra López, S. (2012) "Francisco de Borja y Gandía: la formación del cortesano", dins La Parra, S. i Toldrà, M. (eds.) Francesc de Borja (1510-1572), home del Renaixement, sant del Barroc, Gandia, CEIC Alfons el Vell - IIEB, pp. 83-105.

Labrador, J.J., Di Franco, R. i Cach M. (eds.) (1988) Cancionero de Pedro de Rojas, Cleveland, Cleveland State University.

SCRIPTA, Revista internacional de literatura i cultura medieval i moderna, núm. 9 / juny 2017 / pp. 312-323

ISSN: 2340 - 4841 doi:10.7203/SCRIPTA.9.10349 
Ferran Escrivà-Llorca. Conversaçiones de Música a finals del segle XVI: el cas de l'acadèmia de Joan de Borja i Castro

Lacadena y Calero, E. (1988) "El discurso oral en las academias del Siglo de Oro", El Criticón, pp. $87-102$

Lindell, R. (1994) "Music and Patronage at the Court of Rudolf II", dins Kmetz, J. (ed.), Music in the German Renaissance: Sources, Styles and Contexts, Cambridge, Cambridge University Press, pp. 254-71.

Marek, P. (2011) "Luisa de las Llagas. La abadesa de las Descalzas y el proceso de la comunicación política y cultural entre la corte real española y la imperial", Pedralbes: Revista d'historia moderna 3, pp. 47-90.

Marek, P. (2013) La embajada española en la corte imperial (1558-1641): Figuras de los embajadores y estrategias clientelares, Praga, Karolinum - Universidad Carolina de Praga.

Martínez Hernández, S. (2010) "En la Corte la ignorancia vive [...] y [...] son poetas todos. Mecenazgo, bibliofilia y comunicación literaria en la cultura aristocrática de corte", Cuadernos de Historia Moderna 35, pp. 35-67.

Martínez Millán, J. (1992) “La investigación sobre las élites del poder”, dins Martínez Millán, J. (dir.) Instituciones y élites de poder en la Monarquía Hispana durante el siglo XVI, Madrid, UAM, pp. 11-25.

Martínez Millán, J. (1994) "Familia real y grupos políticos: la princesa doña Juana de Austria (15351573)”, dins Martínez Millán, J. (dir.) La corte de Felipe II, Madrid, Alianza Universidad, pp. 73-106.

Martínez Millán, J. (2013) "La Dinastía Habsburgo en la historiografía española de los siglos XIX y XX”, Librosdelacorte.es 7, año 5, pp. 33-58.

Mazuela-Anguita, A. (2012) Artes de canto (1492-1626) y mujeres en la cultura musical del mundo ibérico renacentista, tesi doctoral, Barcelona, Universitat de Barcelona.

Pastor Zapata J.L. (1992) "La biblioteca de don Juan de Borja, tercer duque de Gandía (+1543)", Archivum Historicum Societatis Iesu, LXI, 121, pp. 275-308.

Sánchez, J. (1961) Academias literarias del Siglo de Oro español, Madrid, Gredos.

Sanhuesa Fonseca, M. (1998) “'Armería del ingenio y recreación de los sentidos’. La música en las academias literarias españolas del siglo XVII”, Revista de Musicología 21, 2, pp. 497-530.

Simón Díaz, J. (1980) "Encuentros del Cardenal F. Barberini con Lope de Vega y con el Príncipe de Esquilache en Madrid, 1626», dins Homenaje al Cardenal Taracón de la Academia de Arte e Historia, Madrid, Archidiócesis de Madrid-Alcalá, pp. 289-316.

Teresko, W. (2014) "The Pietas Austriaca. A Political Myth? On the Instrumentalisation of Piety towards the Cross at the Viennese Court in the Seventeenth Century", dins Karner, H. Ciulisová, I. i García García, B. (eds.), PALATINUM e- Publications, pp.159-180.

Vicente, A. de (ed.) (2008) Tomás Luis de Victoria. Cartas (1582-1606), Madrid, Los Siglos de OroCaja Madrid.

Weiss, R. (1960) "Italian Humanism in Western Europe: 1460-1520", dins E. F. Jacob (ed.) Italian Renaissance Studies, London: Faber \& Faber, pp. 69-93. 